\title{
LA IMAGEN DE CARLOS V Y FELIPE II EN LAS JOYAS DEL SIGLO XVI
}

\author{
POR \\ NATALIA HORCAJO PALOMERO \\ Doctora por la U.C.M.
}

\begin{abstract}
Para conmemorar los centenarios de la muerte de Felipe II y del nacimiento de Carlos V se han estudiado las joyas hechas en el siglo XVI en las que aparecen las imágenes de estos dos monarcas. Así, se han analizado todos los camafeos, miniaturas y otros tipos de piezas con retratos en oro esmaltado. Pero además, se han tenido en cuenta las pinturas en las que aparecen frecuentemente estas piezas, así como un importante número de documentos sobre las mismas.

Palabras clave: Joyería. S. xvi. Carlos V. Felipe II. Jacopo da Trezzo. Leoni

To celebrate the Centenaries of the death of Felipe II and the birth of Carlos V, all of the sixteenth-century jewels in which the images of these kings appear have been examined. In addition to a discussion of cameos, miniatures and other types of portraits in enameled gold, the paintings in which they are frequently depicted as well as selected documents are also considered.

Key words: Jewelery. Xvi century. Felipe II. Carlos V. Jacopo da Trezzo. Leoni.
\end{abstract}

1998 ha sido el gran año de Felipe II. Con motivo del IV Centenario de su muerte, la imagen del Rey, «sobre cuyos dominios nunca se ponía el sol», viva en numerosas pinturas y esculturas reunidas al efecto, ha permitido observar hasta el más insignificante de sus gestos, e igualmente, algún que otro camafeo, nos ha acercado a su rostro o sus hazañas, sin embargo, éstos han sido solamente unos pocos ejemplos de la imagen del Monarca que ha quedado recogida en la joyería que le fue contemporánea, la joyería del siglo XVI.

Por este motivo, lo que se pretende desde estas líneas es rendir un homenaje al Rey desde el mundo de las joyas, ya que se conservan numerosos camafeos con su rostro y algún ejemplo aislado de joya-miniatura, que han quedado sin revisar. Pero sería injusto presentar un estudio pormenorizado de su imagen en las joyas renacentistas, dejando en el olvido la de su padre, Carlos V, que celebró en el 2000 el V Centenario de su nacimiento.

Se ha hecho referencia a joyas, joyas con sus imágenes, pero no solamente analizaremos esos pequeños objetos, lujosos y caros, y en muchas ocasiones perdidos, también estudiaremos los rostros de los Reyes en piezas registradas documentalmente y en cuadros donde aparecen como «detalle anecdótico».

¿Por quién empezar? Si nos atenemos a las celebraciones, lo lógico sería hacerlo por Felipe II, pero las joyas, como arte que son, también presentan características diferentes conforme 
evoluciona un estilo y el tiempo en que éste se desarrolla, por eso, es más oportuno iniciar este estudio por la imagen de Carlos $V$ en las joyas del siglo XVI.

Y quizás sea en las «joyas-retrato» del Rey y Emperador, donde mejor se aprecia la evolución del Medievo al Renacimiento, no sólo en la propia imagen de Carlos, al que podemos ver «cumplir años» en ellas, sino también en su estilo, las joyas de comienzos del siglo XVI son totalmente distintas a las de mediados, será entonces cuando se usen con profusión los camafeos, debido a la aparición de excelentes lapidarios, que siendo en su mayoría italianos, se instalarán en todas las grandes Cortes Europeas al servicio de sus Monarcas.

Las primeras joyas localizadas con la imagen del Emperador son muy similares: Se trata de dos insignias redondas y un medallón igualmente redondo. Son trabajos en oro esmaltado, en los que aparece el busto de Carlos de perfil a la izquierda. De ellos sólo uno lleva impresa la fecha: 1520, pero los tres pueden ser datados alrededor de ese año. La fisonomía del Monarca es similar, cara alargada con el famoso «prognatismo», melena corta con flequillo, gorra en la cabeza, ropa al uso y el collar de la Orden del Toisón sobre los hombros. En cuanto a su estilo, son ejemplares más cerca del gusto artístico Medieval que del Renacimiento, hasta tal punto, que se podrían datar como de fines del siglo xv.

Como las tres joyas llevan inscripciones, parece conveniente estudiarlas individualmente. Empezaremos por la que aparece fechada, y que se conserva en Viena, en el Kunsthistorisches Museum (Fig. 1). En ella, el busto de Carlos, que ha sido trabajado en relieve, por separado, y está unido al fondo mediante un clip «mariposa», no aparece totalmente de perfil, sino que está ligeramente vuelto hacía nosotros, pudiéndosele ver los dos brazos y las manos con los dedos adornados por sortijas. Alrededor, encerrada en un marco, con el borde exterior trabajado a manera de soga, es donde aparece la inscripción en esmalte negro champlevé: «CHARLES + R + CASTILLE + LEEON + GRENADE + ARRAGON + CECILLES + 1520». El texto, en francés, y citando a Carlos como Rey, ha dado lugar a un curioso debate sobre esta joya, que si para algunos estudiosos es borgoñona, para Hackenbroch es trabajo flamenco y en concreto de Malinas ${ }^{1}$. Tampoco se comprende que no aluda al nuevo carácter imperial del Monarca, pero parece que se han querido ver problemas donde no los hay: Carlos todavía no había sido coronado Emperador, se podría decir, en lenguaje actual, que «no había tomado posesión oficial de su cargo», aunque ya gobernaba en los territorios citados y en Flandes, donde además del flamenco se hablaba el francés, de modo que la insignia pudo haber sido hecha efectivamente en Malinas o cualquier otra ciudad flamenca, en homenaje al que sí era Rey «oficial» de los territorios de España.

La otra insignia, también en el Kunsthistorisches de Viena (Fig. 2), es más sencilla en cuanto joya, el busto de Carlos, en relieve, de frente, mostrándonos el brazo y la mano derecha, con el rostro de perfil, practicamente la ocupa toda, y el marco queda reducido a un simple cordoncillo. A ambos lados de su cabeza aparece la inscripción: «PLUS ULTRA», lo que podría hacernos pensar en una fecha sensiblemente posterior, tras la coronación en Aquisgrán, en el momento en el que cambia su lema de Nondum por este nuevo, en que ya se haya recogida su dignidad Imperial. Müller sin embargo, lo data hacia 1520, y para Hackenbroch su manufactura le lleva a pensar en el mismo taller que la anterior ${ }^{2}$. Desde luego son muy similares y la

\footnotetext{
' Steingräber, Erich: Antique Jewellery: Its History in Europe from 800 to 1900. Londres, Thames \& Hudson, 1957, p. 92; Tait, Hugh: «Historiated Tudor jewellery». Antiquaries Journal, n. ${ }^{\circ}$ XLII (1962), p. 227; Fregnac, Claude: Les bijoux de la Renaissance à la Belle Epoque. Alemania, Hachette, 1966, p. 22; Anderson Black, J.: A History of jewels. Londres, Orbis Publishing, 1974, p. 149; Somers Cooks, Anna y otros: Princely Magnificence. Court Jewels of the Renaissance. 1500- 1630. Londres, Debrett Peerage Limited en association with Victoria \& Albert Museum, 1980, pp. 46-47; Newman, Harold: An illustrated Dictionary of jewelry. Londres, Thames \& Hudson, 1996, Char, p. 64, y Hackenbroch, Yvonne, Reinassance Jewellery. Londres, Sotheby Parke Bernet Publications, 1979, p. 230.

${ }_{2}^{2}$ Hackenbroch, Yvonne: Renaissance..., p. 230; Müller, Priscilla E.: Jewels in Spain. 1500-1800. Nueva York, The Hispanic Society of America, 1972, p. 45 y VV.AA.: Reyes y Mecenas, Toledo, Museo de Santa Cruz, 1992, pp. 510- 511, n. 264.
}

AEA, LXXV, 2002, 297, pp. 23 a 38 

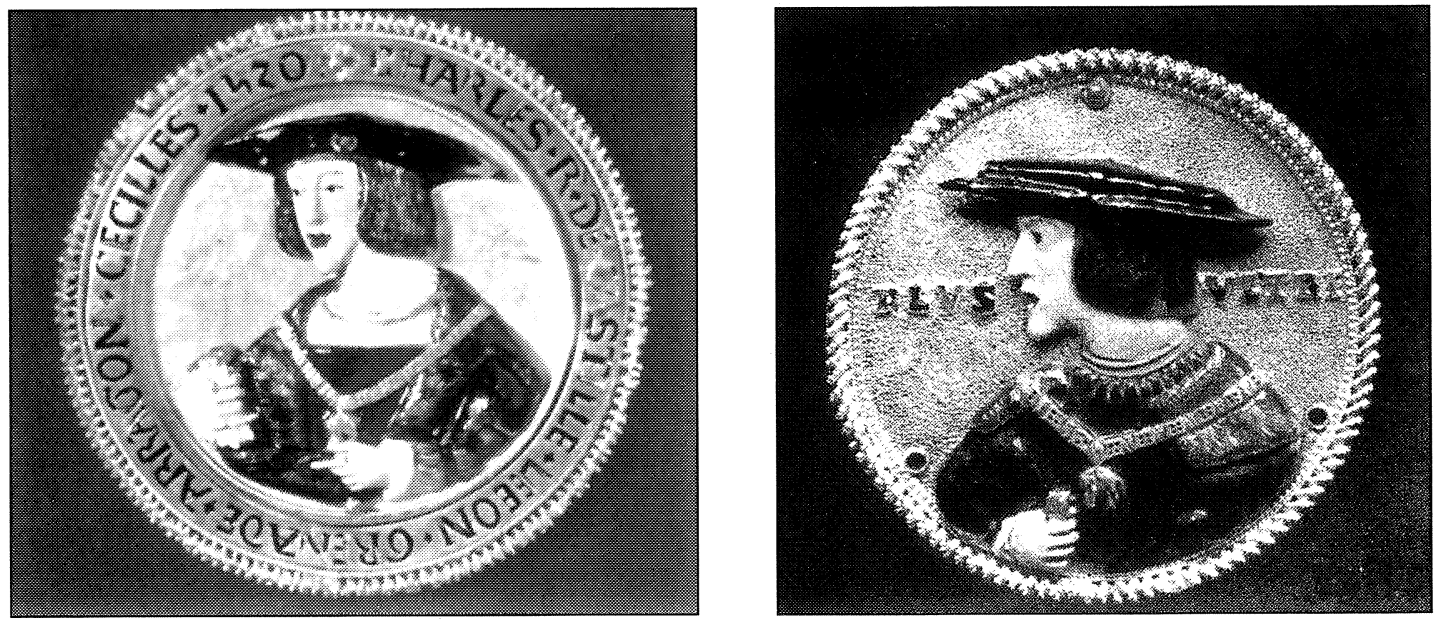

1

2

3
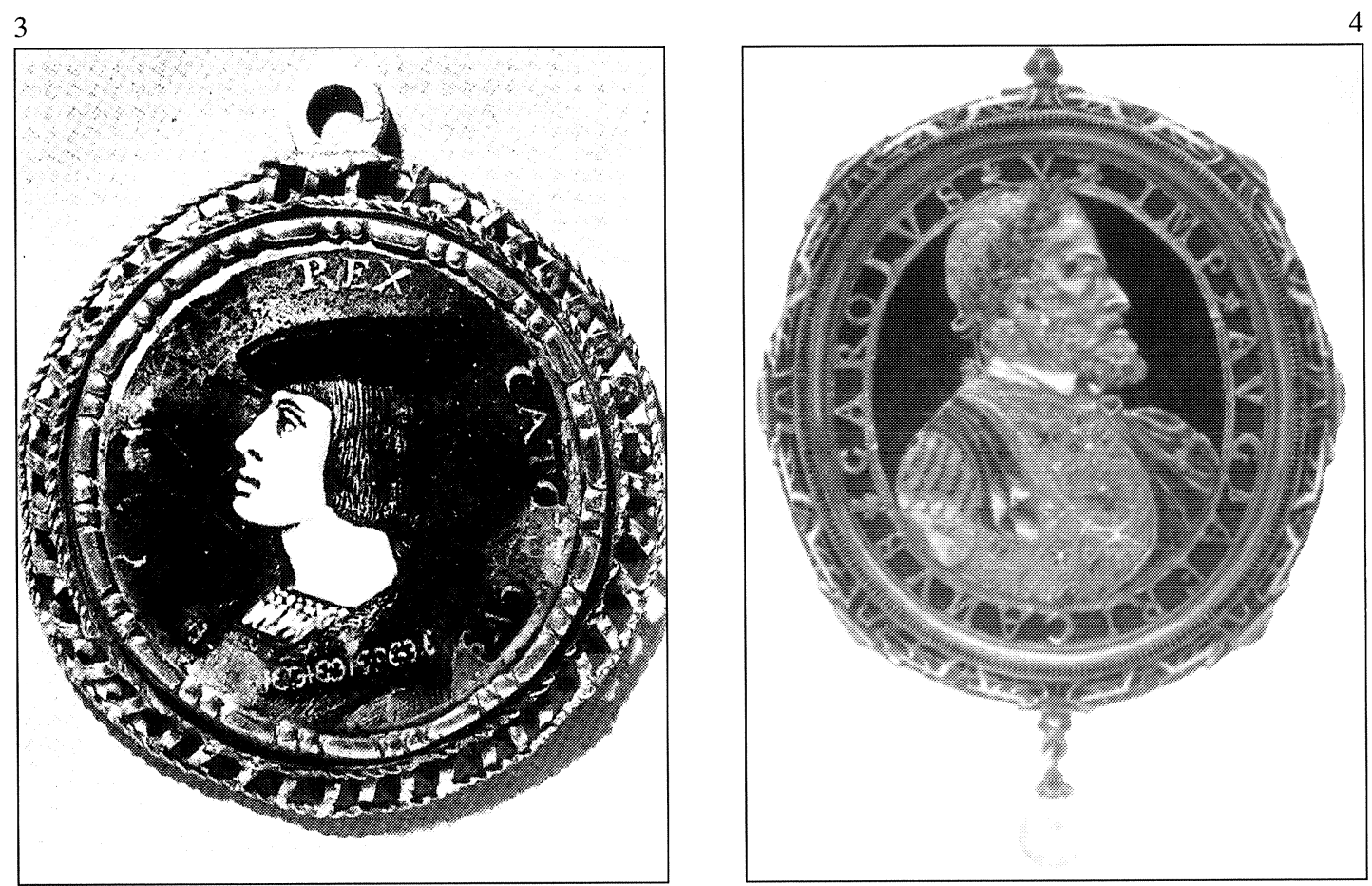

Fig. 1. Insignia redonda en oro esmlatado. Retrato de Carlos V. Malinas, 1520. Kunsthistorisches Museum, Viena.

Fig. 2. Insignia redonda en oro esmaltado. Retrato de Carlos V. Malinas, fines de 1520 (?). Kunsthistorisches Museum, Viena.

Fig. 3. Medallón redondo en plata dorada con esmalte de Limoges. Retrato de Carlos V. Francia, 1517. Colección Michael Friedsan.

Fig.4. Medallón oval en oro esmaltado, heliotropo y lapislázuli, con una perla pinjante. Retrato de Carlos V. ¿Italia?, 1535. Metropolitan Museum, Nueva York.

AEA, LXXV, 2002, 297, pp. 23 a 38 
diferencia de tiempo es tan pequeña que no plantea ninguna dificultad volver a pensar en Malinas o cualquier otro centro flamenco.

El medallón, en la Michael Friedsan Collection, es bastante diferente, para empezar, no es de oro, sino de plata dorada y esmaltada (Fig. 3). En él, Carlos aparece totalmente de perfil y no se le ven ni brazos ni manos. Sus ropas y gorro, esmaltados en rojo, destacan sobre el fondo azul en el que se lee la inscripción: «CAROLVS REX CATOLICVS», completando la joya una montura algo más historiada que la de las insignias arriba estudiadas, ya que la forman un cerco de ovas y un borde de dibujos geométricos calados, en el que se inserta la anilla para poderlo colgar. Como el trabajo es de Limoges, este medallón es considerado francés de hacia 1517, con lo que sería anterior a los citados ${ }^{3}$. La factura de su montura, tosca, podría llevar a pensar en datarla incluso en el siglo xv, sin embargo el retrato del Rey es muy superior al de las insignias anteriores, que le dan una imagen muy en consonancia con sus retratos flamencos de ese tiempo, y si bien aquí hay una mayor idealización, —el prognatismo está muy mejorado-, y mucho más esquematismo, - es un esmalte de escuetos perfiles-, Carlos parece retratado de forma más cercana al natural y por comparación, este retrato parece posterior en cuanto a su calidad, aunque no se puede obviar la inscripción que sólo le reconoce como «Rey Católico» sin aludir para nada a su dignidad imperial, por lo que 1517 parece, en principio, una fecha correcta.

La siguiente joya, donada por J. Pierpont Morgan al Metropolitan Museum, es un medallón, ligeramente oval, de gran calidad (Fig. 4 ), y ya es un ejemplar plenamente renacentista. En su parte central, sobre una lámina de heliotropo, aparece el busto de Carlos de perfil a la derecha, en oro esmaltado, rodeado por una inscripción en letras de oro sobre un cerco de lapislázuli que dice: «CAROLVS. V. IMP. AVG. AFRICANVS». (Carlos V, Emperador Augusto Africano). Cierra la composición una montura también en oro esmaltado, decorada con arabescos y cartelas, con una perla oval pinjante en su base, lo que confiere una mayor suntuosidad a esta joya, sobre la que se ha escrito mucho y sobre cuyos comentarios se hace necesario hacer una pequeña reflexión. El medallón fue en un primer momento datado alrededor de 1540 y se pensaba que posiblemente estuviese inspirado en una medalla realizada por Leone Leoni ${ }^{4}$, pero Hackenbroch lo ha fechado en 1536 y adjudicado, como ya lo había hecho Williamson, sin ningún tipo de argumentos, a Leoni ${ }^{5}$. La fecha no parece ofrecer muchas dudas, Carlos es nombrado en el medallón Emperador Augusto Africano, y ciertamente había sido en 1535 cuando había conseguido su espectacular triunfo sobre los turcos en Túnez, y como dice Fernández Álvarez, regresaba de la campaña militar «como los antiguos emperadores romanos» ${ }^{6}$ y de hecho así se muestra en el retrato, a la romana, coronado de laurel como podemos ver a los césares en numerosos camafeos clásicos, haciendo honor a la inscripción que le llama $\mathrm{Au}$ gusto. También es cierto que no se dirigía hacia España, sino que encaminó sus pasos a Italia, visitando Sicilia y Nápoles para pasar luego a Roma y de allí a Milán desde donde planeaba dirigir la operación contra Francisco I. Y en Milán se encontraba trabajando en aquel momento Leone Leoni. Sin embargo no se ha localizado ningún documento que le atribuya esta joya, por lo que no puede haber una adjudicación sin dudas, aunque indudablemente, la calidad del

\footnotetext{
${ }^{3}$ Hackenbroch, Yvonne: «Some portraits of Charles V». The Metropolitan Museum of Art,n. 27 (1969), p. 323 y Williamson, G.C.: Catalogue of the Collection of jewels and precious works of Art. The property of J. Pierpont Morgan. Londres, Chiswick Press, MCMX, pp. 41-42.

${ }^{4}$ Dennis, Faith: Renaissance Jewelry. Nueva York, The Metropolitan Museum of Art. A picture book, 1943, lám. 2; Wagner de Kertesz, M.: Historia universal de las joyas. Buenos Aires, Ediciones Centurión, 1947, p. 412 y Fregnac, Claude: Les bijoux ..., p. 22.

${ }^{5}$ Williamson, G.C.: Catalogue...,pp. 29-30, n. ${ }^{\circ}$ 18; Hackenbroch, Yvonne: «Some Portraits...» p. 327; Hackenbroch, Yvonne: «Gioielli italiani del Rinascimento at Metropolitan Museum of Art». Antichita Viva, XIV (1975), p. 49 y Hackenbroch, Yvonne: Renaissance... p. 38.

${ }^{6}$ Fernández Álvarez, Manuel: Carlos V. Un hombre para Europa. Madrid, Espasa Calpe, 1999, p. 199.
}

$A E A, \mathrm{LXXV}, 2002,297$, pp. 23 a 38 
trabajo y la presencia de piedras duras, heliotropo y lapislázuli, hablan de un orfebre italiano de primera línea.

Otra joya con la imagen del Rey y Emperador, en el Kunsthistorisches Museum (Fig. 5 ), es una insignia oval con un camafeo de ónice, con el retrato de busto de perfil a la derecha, tallado en blanco sobre fondo azul, rodeado por una montura con roleos y volutas de oro esmaltado y engarzado con rubíes cuadrados, talla tabla, en monturas piramidales. En el reverso, tiene una lámina de oro esmaltada con el Águila Bicéfala de los Habsburgo, la inscripción «PLUS ULTRA», las dos columnas de Hércules, las armas de Austria y Castilla y el Collar del Toisón. Sobre su fecha y origen, la situación no puede ser más complicada, Kenner apenas aporta datos ${ }^{7}$, otros no van mucho más allá y simplemente hablan de un posible origen italiano y de mediados de siglo, sin dar ninguna explicación ${ }^{8}$. Pero tanto en Hackenbroch como en Somers Coks, ya aparece un estudio más serio: La primera considera la montura trabajo francés de hacia 1570, y en cuanto al camafeo le atribuye, aunque sin datarlo, un origen milanés ${ }^{9}$. Somers Cocks opina que la montura es de finales del siglo, sin citar lugar de ejecución, mientras que cree que el camafeo puede ser alemán, relacionándolo con el trabajo del medallista Joachim Deschler, activo en Nuremberg entre 1540 y $1569^{10}$. ¿Qué puede añadirse a esto? Es muy difícil ubicar una pieza de orígenes tan controvertidos, sin ningún tipo de marca o de documentos que la avalen, sin embargo parece más fácil su datación: La joya presenta en el reverso, todos los símbolos de un Rey y Emperador que ejerce de tal, pues van acompañando a su imagen: Un retrato de Carlos tocado otra vez con la gorra de las primeras piezas analizadas, pero desprovisto de la juventud que mostraba en ellas, incluso de la madurez del medallón estudiado anteriormente, es un hombre mayor, posiblemente de cincuenta y tantos años, lo que permitiría fechar la insignia alrededor de 1555, antes de su retirada a Yuste, además, la montura no parece de finales de siglo, sino de mediados y aunque es probable que sea de distinta mano que el camafeo, lo que si es cierto es que la una se hizo para el otro.

Las dos joyas restantes con el retrato de Carlos son más díficiles de comentar, puesto que no se ha podido localizar ninguna imagen gráfica suya. Del primer ejemplar sólo se puede señalar que se trata de un camafeo con el busto tallado en ónice del Monarca en armadura y con una corona de laurel, y que se conservaba en la Bibliothèque Impériale de París a mediados del siglo XIX ${ }^{11}$. La otra joya, propiedad de Lady Charlotte Schreiber, es muy curiosa y distinta a las ya expuestas. Se trata de un medallón redondo de oro esmaltado que representa a Carlos $\mathrm{V}$ en un orbe salpicado de estrellas que es mecido por el Diablo, con las figuras de la Muerte y la Guerra a los lados, rodeado todo por la siguiente inscripción: «CAROLUS V. STERNSEE. IN TE DOMINE SPERAVI». (Carlos V. Estrella en el mar. ¡En tí Señor confié!). Según Robinson, un viejo libro de heráldica es quien proporciona el significado de esta alegoría: Cuando Carlos V estaba visitando las ciudades del Norte de su Ducado paterno, un noble frisio, llamado Humelda, que era gobernador de Harlingen, le avisó que no se embarcase en el Zuidersee con sus tropas, porque iba a estallar una tempestad. El Emperador accedió a sus ruegos y no lo hizo, quedando sobrecogido cuando le comunicaron que había sucedido lo anunciado por $\mathrm{Hu}-$ melda, perdiéndose barcos y hombres, y entonces, agradecido, le regaló este medallón ${ }^{12}$.

\footnotetext{
${ }^{7}$ Kenner, Fiedrich: «Cameen und modelle des XVI. Jahrhunderts» Jahrbuch des Kunsthistorisches Sammlungen, IV ( 1886), taf. III.

${ }^{8}$ Rossi, Filippo: Orificeria Italiana. Dall XI al XVIII Secolo. Milán, Industrie Grafiche Editoriale, S. P. A. 1974, Tav. 62 y Anderson Black, J.: A History..., p. 150.

${ }^{9}$ Hackennbroch, Yvonne: Renaissance..., p. 99.

${ }^{10}$ Somers Coks, Anna y otros: Op. cit., pp. 68- 69, n. 66

${ }^{11}$ Chabouillet, M.: Catalogue général et raisonné des camées et pierres gravées de la Bibliothèque Impériale. París, J. Claye, s/a, p. 71, n. $^{\circ} 369$.

12 Robinson, J.C.: Catalogue of the special loan exhibition of Spanish and Portuguese ornamental Art. Londres, Chapman \& Hall, 1881, p. 109, n. ${ }^{\circ} 687$.
} 
Bastante distinta es la imagen de Felipe II en las joyas del siglo XVI, practicamente todas ellas camafeos, atribuidos en un alto porcentaje a Jacopo da Trezzo. Son joyas menos ricas que las de su padre, ya que el camafeo es su protagonista absoluto, quedando la montura, menos en algún ejemplo, reducida a un breve cerco de oro esmaltado. Para Jean Babelon, los camafeos con la imagen del Rey que pueden ser relacionados con el tallador italiano son los siguientes: Cuatro ejemplares en la Galeria de los Uffizi en Florencia, dos en el British Museum de Londres, uno en el Gabinete de Medallas de París, otro en la Colección Real en Windsor, uno más en el Museo Victoria \& Albert de Londres, y dos más en las colecciones Arundel y Marlborough ${ }^{13}$.

Todos los ejemplares citados e incluso algunos más, han podido ser localizados, aunque la falta de información gráfica sobre varias de estas joyas, hace extremadamente difícil su estudio, e impide, que por la imagen que en ellos ofrece el Monarca, se les pueda ordenar cronologicamente, por lo que es aconsejable empezar el análisis por aquellos camafeos más documentados y dejar para el final los ejemplos de los que practicamente se desconoce todo.

El camafeo de la Colección Real del Castillo de Windsor, presenta el retrato de perfil a la izquierda del Rey tallado en un ónice oval, con una fina montura de oro a manera de cerco, y una anilla para su suspensión en el ápice. Según Smith, aparece reseñado en el Catálogo de Van Der Doort como sigue: «Item, otra piedra ágata del rey Felipe de España, siendo la cabeza blanca, el pecho azulado y el fondo transparente como un cristal, entregado por mí al Rey» ( y en el margen está anotado) «Dada al Rey, 1637» ${ }^{14}$. La joya, por la fecha indicada, se tuvo que entregar a Felipe IV, pero la imagen que su abuelo Felipe II muestra en ella podría llevar a datarla alrededor de 1560, cuando ya ha asumido el poder y Trezzo ha entrado a trabajar a su servicio, aunque es muy difícil, al carecer de datos, adjudicarle este camafeo sin ninguna discusión.

Los dos camafeos del British son distintos, el catalogado con el n..$^{\circ} 382^{15}$, tallado en un ónice circular, muestra al Rey de perfil a la derecha, con una fina montura de oro considerada trabajo del siglo XviII. Pertenecía a la Colección Carlisle y fue adquirido por el Museo en 1890. De los dos, parece el de peor calidad, y por comparación con el anteriormente expuesto, podría ser algo anterior, pues la imagen que ofrece el Rey es más joven. El n. ${ }^{\circ} 3811^{16}$ es mucho más interesante, también se trata de un ónice, ovoide, tallado de manera que el busto, de perfil a la derecha, destaca en blanco sobre el fondo obscuro. Fue adquirido por el Museo en 1895 de la Colección Franks. Es un retrato muy bueno, con un excelente trabajo de talla de los cabellos y la armadura del Monarca, que se muestra con las cejas ligeramente arqueadas, gesto que puede observarse en un busto de mármol del Metropolitam Museum, legado de Annie C. Kane, atribuido al taller de Leone Leoni en la segunda mitad del siglo Xvi. Parece un hombre de cincuenta y tantos años, por lo que tal vez podría datarse en la década de 1570 . Ambos camafeos han sido relacionados con Trezzo, pero como en el anterior, la adjudicación carece de argumentación, por lo que el problema que se plantea sigue siendo el mismo, y se complica aún más en el segundo caso, donde se ha señalado el parecido con la pieza del taller de Leoni.

De los cuatro ejemplares conservados en los Uffizi, es necesario señalar que su paradero actual es el Museo degli Argenti del Palazzo Pitti. Tres de ellos, catalogados con los n. ${ }^{\circ} 125$, 126 y 131, son retratos en solitario de Felipe II, el n. ${ }^{\circ} 127$, con la doble imagen del Rey y su

\footnotetext{
${ }^{13}$ Babelon, Jean: Jacopo Da Trezzo et la construction de L'Escurial.Essai sur les arts a la Cour de Philippe II. 15191589. Madrid, Dossat, 1922, p. 242, nota 3 y pl. VII, n. ${ }^{\circ} 4,5$ y 8.

${ }^{14}$ Smith, Cliford H. : «The King's gems and jewels at Windsor Castle». Connoiseur, IV ( 1903 ), pp. $241-242$.

${ }^{15}$ Dalton, O.M. : Catalogue of the engraved gems of the post-classical periods in the deparment of British and mediaeval Antiquities and ethnography in the British Museum. Londres, Printed by Order of the Trustees, 1915, pag. 52.

${ }^{16}$ Ibidem, p. 51.
}

$A E A, \mathrm{LXXV}, 2002,297$, pp. 23 a 38 
hijo, será estudiado más adelante. El n. ${ }^{\circ} 125$, se trata de un camafeo oval de calcedonia, engastado en una montura muy simple de oro esmaltado con roleos, con dos anillas, una en el ápice destinada a la sujeción, y otra en la base que ha perdido la perla que sin duda llevaba pinjante. El Rey aparece de perfil a la derecha, también con las cejas arqueadas, y aunque posiblemente sea de la misma época, la calidad de la talla es peor. Este camafeo se mostró en el Museo del Prado en la Exposición Felipe II, un Príncipe del Renacimiento, y en su catálogo se nos señala que se trata de un trabajo anónimo, aunque quizás pueda ser atribuido a Annibale Fontana, un escultor y lapidario influenciado por Trezzo, pudiendo haber sido comprado por el Cardenal Fernando de Médicis en Roma entre 1571 y $1587{ }^{17}$. No hay más datos y poco más es lo que se puede decir sobre este camafeo del que ya se ha advertido que en comparación con el anterior es pobre y su calidad inferior. El n. ${ }^{\circ} 126$, del que no se ha podido obtener reproducción gráfica, es un ónice con el busto del Monarca, y el n. ${ }^{\circ} 131$, es un camafeo muy peculiar, una esmeralda, cuadrada, de ángulos romos, bordeada de un filo de oro trabajado en filigrana. En ella, de perfil a la derecha, se nos muestra un Felipe II aún joven, con barba y armadura ${ }^{18}$.

Otro de los camafeos localizados atribuidos a Trezzo es el del Museo Victoria \& Albert, catalogado con el n. $.^{\circ} 2628-55$. Se trata de un camafeo de ónice considerado trabajo italiano de la segunda mitad del siglo xvI y que fue adquirido por tres libras y treinta y cinco peniques ${ }^{19}$. No se puede realizar una mejor descripción de este ejemplar por carecer de su reproducción gráfica, lo cual también dificulta enormemente su datación y posible estudio. Lo mismo ocurre con las restantes piezas atribuídas a Trezzo, de las haremos una simple mención: El camafeo con n. ${ }^{\circ} 979$ en el Gabinete de Medallas de París, posiblemente sea el que se guardaba a mediados del siglo pasado en la Bibliothèque Impériale, un ejemplar de ónice de dos lechos, con el retrato de Felipe II con armadura y toisón, y del que no se aporta ningún otro dato ${ }^{20}$. Del de la Colección Arundel sólo se puede señalar que tenía el n. ${ }^{\circ} 366$ y algo más puede indicarse sobre el de la Marlborough, con n. ${ }^{\circ} 586$ y anteriormente en la Colección Bessborough. De este se sabe que se vendió en 1899 por cien Guineas y que recuerda al del Castillo de Windsor, aunque es algo más alargado y tiene una inscripción (?) en el reverso que hace pensar que se trató de un regalo del Rey o bien a su esposa María Tudor o a su hermanastra Isabel ${ }^{21}$. Como Isabel I gustaba de regalar joyas con su imagen, bien en oro, miniatura o camafeo, es posible que ella fuese la destinataria del objeto y logicamente lo tuvo que recibir con anterioridad al enfriamento de las relaciones entre ambos Monarcas y por supuesto antes del envío a Inglaterra de la famosa Armada Invencible (1588).

De las restantes joyas con la imagen de Felipe II, merece la pena destacar un camafeo perteneciente a una colección privada desconocida (fig. 6 ). Tallado en una sardónica oval de dos lechos, el busto, en blanco, de perfil del Rey, con armadura y Toisón, destaca sobre el fondo negro. La montura, vistosa, en oro esmaltado con volutas, tiene un pequeña perla pera pinjante en la base, y en la parte superior, restos de eslabones, de lo que serían dos cadenas por las que se colgaría. Para Hackenbroch es trabajo italiano/español de hacia $1560{ }^{22}$. Posiblemente la doble nacionalidad hace alusión a que el camafeo procede de Italia y la montura es española, lo cual no es discutible, sí la fecha: El camafeo muestra a un Felipe II viejo, y la montura, por sus motivos decorativos está más cerca del siglo XVII que del xVI, por lo que probablemente sea una joya de la década de 1590.

\footnotetext{
17 VV.AA.: Felipe II, un Príncipe del Renacimiento. Madrid, Museo del Prado. 1998, pp. 664- 665, n. 284 y Aschengreen Piacenti, Cristina: Il Museo degli Argenti a Firenze. Milán, Electra, 1967, p. 182, n. 982.

${ }^{18}$ Aschengreen Piacenti, Cristina: Op. cit., p. 182, n. ${ }^{\circ} 983$ y 988.

${ }^{19}$ Robinson, J. C.: Op. cit ., p. 145 y Dalton, O. M.: Op. cit., p. 51.

${ }^{20}$ Chabouillet, M.: Op. cit., p. 71, n. $^{\circ} 370$.

${ }^{21}$ Smith, Cliford H. : Op. cit., pags. 241- 242 y DALTON, O.M. : Op. cit., p. 51.

${ }^{22}$ Hackenbroch, Yvonne: Renaissance... p. 317.
} 

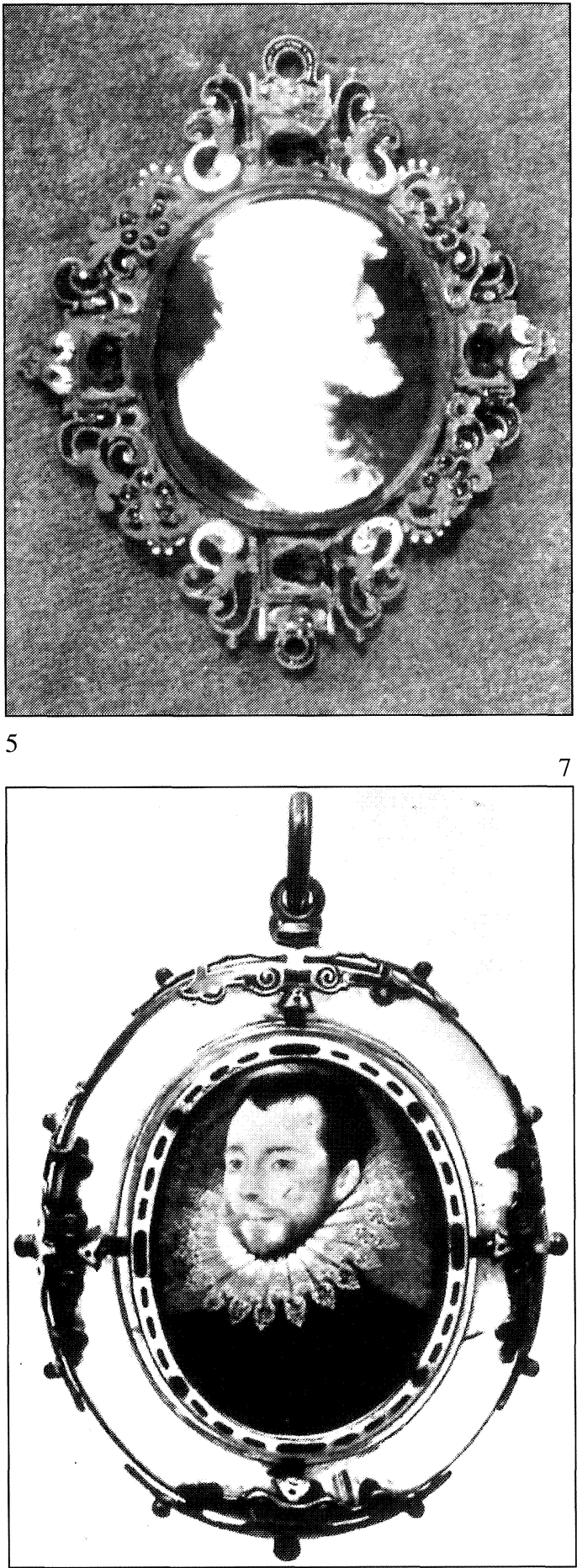

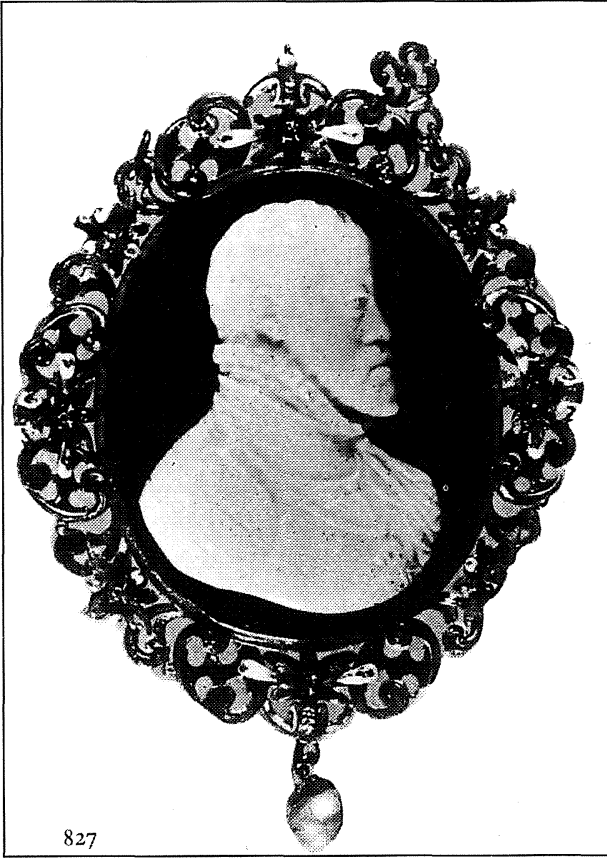

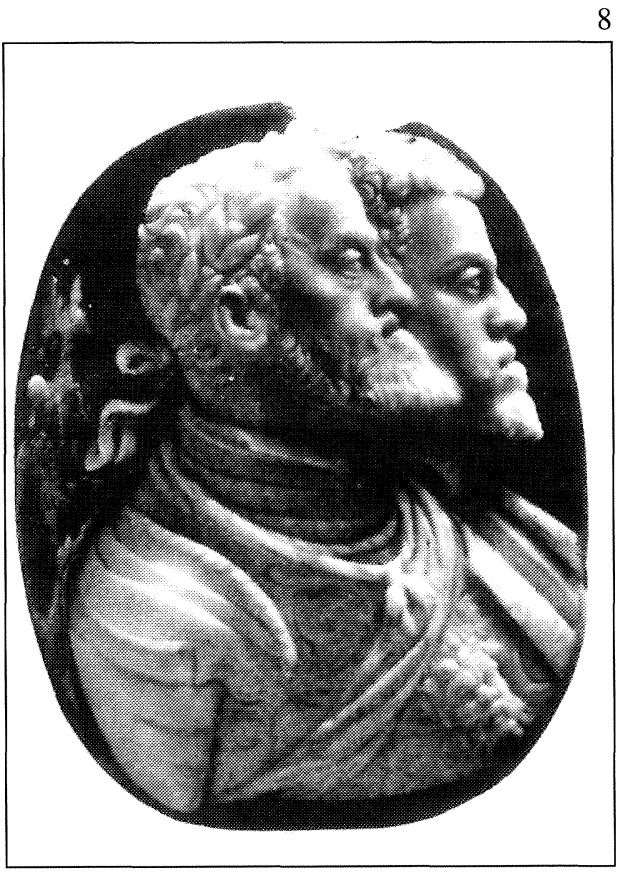

Fig. 5. Insignia oval en oro esmaltado con rubíes y un camafeo de ónice. Retrato de Carlos V, h.1555. Kunsthistorisches Museum, Viena.

Fig. 6. Medallón oval en oro esmaltado con una perla pinjante y un camafeo de sardónica. Retrato de Felipe II, España/ Italia, h. 1590. Colección privada.

Fig. 7. Medallón oval de cristal de roca con oro esmaltado y una miniatura atribuida a Isaac Oliver. ¿Retrato de Felipe II?, Inglaterra, h. 1550- 1560. Colección privada (?)

Fig. 8. Anverso del camafeo oval en sardónica atribuido a Leone Leoni. Retratos de Carlos V y Felipe II. Italia, 1550. Metropolitan museum, Nueva York.

AEA, LXXV, 2002, 297, pp. 23 a 38 
Aún hay noticias de otras cinco joyas, aunque poco documentadas y sin localizar gráficamente. Dos de ellas, camafeos, han sido catalogados por Robinson y se conservan en el Victoria \& Albert. El n. ${ }^{\circ} 312$ fue legado por el Baron Davillier, es una calcedonia con la cabeza de perfil de Felipe II, y se considera posible trabajo de Trezzo. El otro, con n. ${ }^{\circ} 389$, legado por M. F. Spitzer, es de ónice y tiene una montura de oro esmaltado, datado hacia $1580^{23}$. El tercero, igualmente un camafeo, anteriormente en la colección Oppenheimer, fue subastado en Christie's en 1936: Se trata de un ónice, probablemente con el retrato del Rey, de perfil a la izquierda, en una montura de oro esmaltado con roleos y tres perlas peras pinjantes en la base, catalogado como italiano y fechado en el siglo XVI ${ }^{24}$. La cuarta joya, también un camafeo, posiblemente en Viena, es atribuido por Jean Babelon a Trezzo o a alguno de sus discípulos. En él aparece, en el anverso, Felipe II de tres cuartos, en perfil a la izquierda, con sombrero alto y gola al cuello, rodeado de la siguiente leyenda: «PHILIPPVS. II. C. V. F. REX. HISP. NON. SVFFICIT. ORBIS» (Felipe II, hijo de Carlos V, Rey de los españoles, el orbe de la tierra no le basta), y en el reverso, un caballo corriendo hacia la izquierda, sobre el globo terráqueo ${ }^{25}$. Aún menos es lo que se ha podido saber sobre el quinto ejemplar, del que Jean Babelon señala que se trata de un medallón oval con la efigie de Felipe II y la leyenda: «PHI. REX. HISPANIARVMET» (Felipe Rey de los españoles también), y que seguramente es obra de Trezzo ${ }^{26}$.

Hay por último otra joya cuya subasta en Christie's en Junio de 1535, fue anunciada en la revista Apollo,(Fig. 7). Es un colgante-medallón, oval, de cristal de roca, montado en oro esmaltado con cartelas recortadas, que sirve de marco a una miniatura realizada igualmente en esmalte, de ¿Felipe II? de perfil a la izquierda, atribuida a Isaac Oliver ${ }^{27}$. No parece el Rey, aunque así lo comunicaba la casa inglesa de subastas. El personaje retratado es un joven de unos treinta y tantos años (i1550-1560?), vestido de obscuro con una gola de encaje próxima a la moda inglesa del reinado de Isabel I, en cuya corte ya trabajaba Oliver, discípulo de Hilliard, que había nacido en Francia (Rouan), alrededor de 1555-1556 y cuya vida transcurre practicamente en Inglaterra donde falleció en 1617. ¿Es Felipe II? ¿Lo pintó Oliver? Si consideramos, dejando aparte del problema de las fechas, que el miniaturista no había visto en su vida al Rey, y que copió su imagen de algun retrato enviado por éste a María Tudor, pues es posible, pero no parece demasiado convincente debido al escaso parecido físico.

No terminan aquí las joyas-retratos de Carlos y Felipe, hay un grupo extremadamente singular por tratarse de ejemplares con retratos dobles e incluso triples, todos ellos camafeos. Uno de los más documentados es una sardónica oval, sin montura, que tiene en el anverso su doble imagen y en el reverso a su esposa y madre, Isabel de Portugal. En el Metropolitan Museum, procede de la Colección Milton Weil (Figs. 8 y 9). También se le vió en la exposición del Prado, pudiendo ser contemplado en sus dos caras gracias a un montaje de espejo muy acertado. Hackenbroch, al referirse a él, lo considera de Leone Leoni y lo data en $1550^{28}$, si bien no realiza ningún tipo de argumentación sobre esta atribución. No ocurre lo mismo en el catálogo de la anteriormente citada exposición, en el que el camafeo aparece profusamente documentado en su relación con Leoni ${ }^{29}$, aunque los datos que proporciona están extraídos de la obra de Plon ${ }^{30}$. Leoni envió una carta a Granvela el 20 de Diciembre de 1550, notificándole que esta-

\footnotetext{
${ }^{23}$ Robinson, J. C. : Op. cit., p. 74 , n. 312 y p. 81 , n. 389.

${ }^{24}$ Christie's: Catalogue of the Henry Oppenheimer Collection. The highly important collection of Mediaeval and Renaissance works of Art. Londres, 1933, p. 31, n. ${ }^{\circ} 63$

${ }^{25}$ Babelon, Jean: Op. cit., pp. $244-245$.

${ }^{26}$ Ibidem, p. 202, nota 1.

${ }^{27}$ Apollo, XXII (1935), p. 114.

${ }^{28}$ Hackenbroch, Yvonne: «Some portraits...», p. 328

${ }^{29}$ VV.AA: Felipe II..., pp. 537- 538, n. ${ }^{\circ} 181$.

${ }^{30}$ Plon, Eugene: Leone Leoni, sculpteur de Charles Quint et Pompeo Leoni sculpteur de Philippe II. París, Libr. Plon, 1887.
} 
ba trabajando en un camafeo con los retratos del Emperador, su esposa y su hijo, y que pensaba ofrecérselo a Carlos como regalo. Sin embargo, Plon advierte que no le ha sido posible localizar este camafeo y Angulo, que también conoce su existencia, le da por desaparecido ${ }^{31}$. ¿Es el camafeo de las cartas de Leoni? En principio así lo parece, incluso el retrato, en primer plano del Emperador, de perfil a la derecha, coronado de laurel, recuerda su imagen del medallón del Metropolitan, aunque aquí aparece ligeramente envejecido, como correspondería a los cincuenta años que tenía en 1550, e igualmente el retrato del Príncipe, que asoma tras él, también se corresponde con los veinte y tres años que tendría en aquella fecha. Distinto es el retrato de la Emperatriz, de perfil a la izquierda y que siendo tallado post mortem, no le hace demasiada justicia, pues la muestra con un rostro de gesto mohíno y facciones muy duras. Podría afirmarse que tiene más calidad el anverso que el reverso, y sería interesante señalar un pequeño detalle que aparece en el primero: A la espalda de los dos hombres y cerca del borde de la piedra, hay tallada una figura extraña: ¿Son dos águilas en vuelo unidas por el cuello? Si así fuera, al ser la divisa de los Habsburgo un águila bicéfala, aquí estaríamos ante un águila acéfala pero de dos cuerpos. ¿Qué quiere darnos a entender este símbolo? ¿Se ha querido indicar que padre e hijo son las cabezas de esos cuerpos? ¿Hay alguna referencia a la futura división territorial de los Habsburgo, ya planteada en 1547 y de ahí que cada cabeza necesite un cuerpo? Imposible de momento, descrifar este enigma. Y aún se complica un poco más la situación, ante la noticia proporcionada por Ernest Babelon, de que la Colección Imperial de Viena conservaba un camafeo, representando a Carlos V, Isabel de Portugal y su hijo Felipe, atribuido a Trezzo $^{32}$. Ha sido imposible localizar una representación gráfica o documental de este ejemplar, por lo que se desconoce si se trata de la misma joya o es otra diferente.

El siguiente camafeo es menos complicado de estudiar, se conserva en el Gabinete de Medallas de París, donde fue adquirido en 1896. De forma oval, es una sardónica de dos lechos, en la que sobre un fondo azul- grisáceo destaca, en blanco, el doble perfil a la derecha de Carlos V y su hermano, el futuro Emperador Fernando I. La montura que lo rodea es un simple cerco de oro esmaltado con cartelas recortadas en los ejes, con engarces y anillas vacíos que permiten suponer la existencia de piedras y perlas perdidas. Somers Coks cree que la edad del Emperador en este camafeo es de treinta años, y opina igual que Matthew Gebel que lo data en 1530, sin embargo da a la montura una fecha posterior en torno a $1575^{33}$. No parece que pueda haber problemas en cuanto a la datación del camafeo, pero el tema de la montura es distinto, nada en ella parece señalar una fecha tan tardía, y bien podría haberse realizado a la vez que se talló la piedra. No hay alusiones al lugar donde se ejecutó esta joya y al no haberse localizado ningún dato al respecto, no puede hacerse ninguna aportación concluyente, si bien puede pensarse en unas manos italianas para el camafeo y un trabajo alemán o español para la montura.

No es esta la única joya en que aparecen Carlos y Fernando: Conserva el Museo Victoria \& Albert una sortija de plomo, que puede ser utilizada como un silbato, en que están representados los bustos de ambos hermanos. Está catalogada como trabajo alemán de mediados del siglo XVI y anteriormente formó parte de la Colección Waterton.

Otro de los ejemplares, un camafeo oval de sardónica, tallado con los retratos de perfil a la izquierda de una pareja, en blanco sobre fondo azulado, en una montura de oro esmaltado, con temas geométricos y cartelas recortadas, y con una perla a manera de fresa pinjante (Fig. 10), plantea una ligera polémica: Rossi le cita como trabajo italiano del siglo XVI en el Kunthistorisches Museum y no dice quién son los retratados ${ }^{34}$, mientras que Hackenbroch, señala que son Felipe II y su primera esposa María Manuela de Portugal, que es un trabajo italo-español de hacia 1545-1550, y que pertenece a una colección privada desconocida ${ }^{35}$. Efectivamente, así parece ser, el retrato masculino bien puede ser el de un Felipe II que ronda los veinte años,

AEA, LXXV, 2002, 297, pp. 23 a 38 

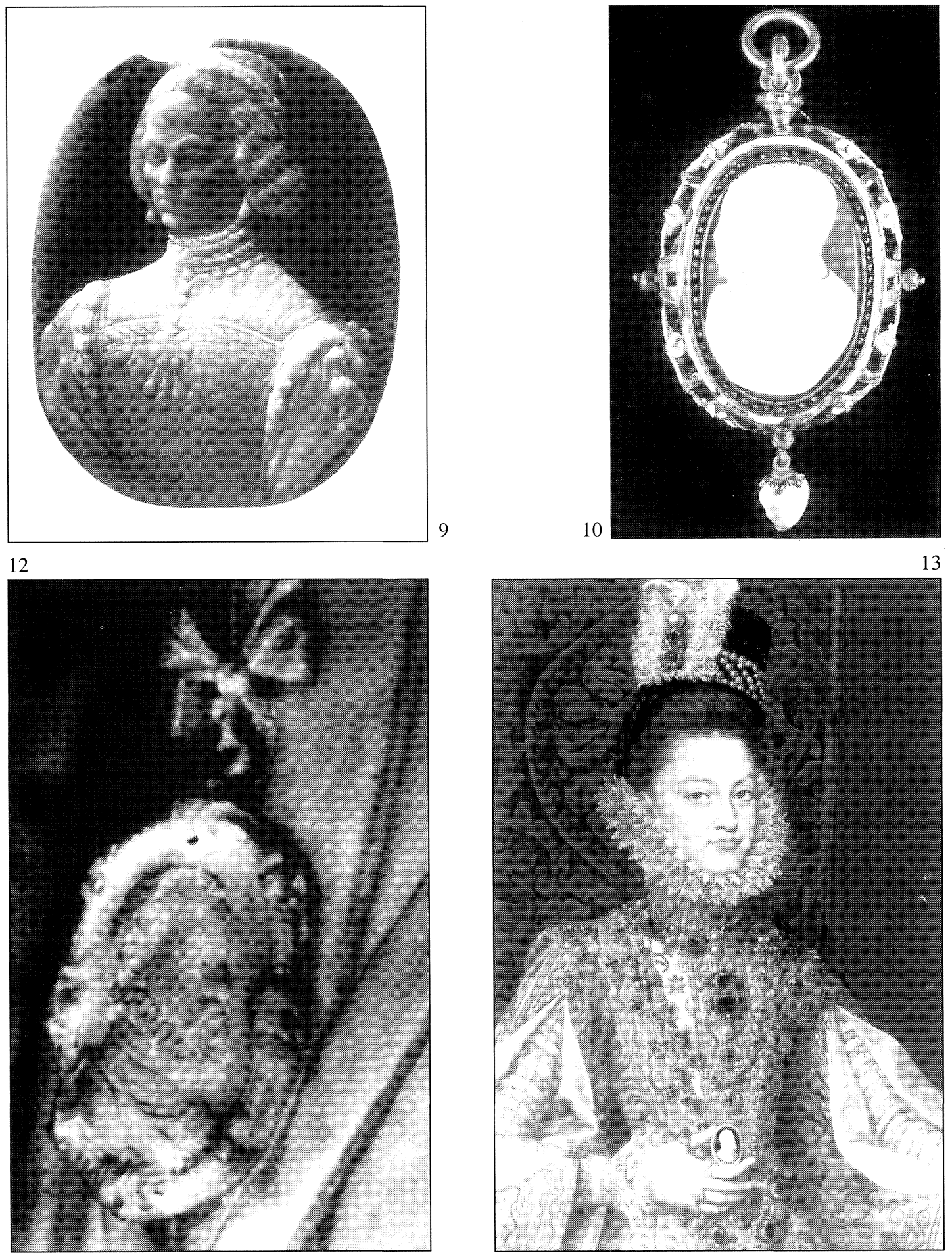

Fig. 9. Reverso del anterior: Retrato de Isabel de Portugal.

Fig.10. Medallón oval en oro esmaltado con una perla pinjante y un camafeo de sardónica. Retratos de Felipe II y María Manuela de Portugal. España/ Italia, 1545-1550. Colección privada.

Fig. 12. Detalle del camafeo de Felipe II en el retrato de Juana de Portugal, obra de Pompeo Leoni, de 1574, en el Monasterio de las Descalzas Reales de Madrid.

Fig. 13. Detalle del camafeo de Felipe II en el retrato de Isabel Clara Eugenia y Magdalena Ruiz, de Alonso Sánchez Coello, de h. 1585-1588, en el Museo del Prado de Madrid.

AEA, LXXV, 2002, 297, pp. 23 a 38 
mientras el de su esposa queda más en entredicho por no poderse comparar con ningún retrato de ella, y si bien el camafeo puede ser italiano, su montura tal vez sea española.

También aparece Felipe II en otro camafeo oval de ónice, tallado de perfil a la derecha, en blanco sobre fondo obscuro, con el retrato de su hijo Carlos, de perfil a la izquierda, en el envés de la piedra. Tiene una montura de oro esmaltado, con un leve cerco interior de ovas y un borde exterior de temas geométricos y vegetales, con una anilla en el ápice para su suspensión. Este camafeo se mostró en la exposición del Prado con el mismo montaje de espejo ya citado. Según Jean Babelon atribuido a Trezzo, se guardaba en la Galeria de los Uffizi en Florencia con el n..$^{\circ} 127^{36}$, y efectivamente este es el número de catálogo con el que se conserva, pero en el Musęo Degli Argenti. El Prado baraja como posible la atribución a Trezzo ${ }^{37}$ y aporta varios datos sobre él, recogidos anteriormente por Tuena y Massinelli ${ }^{38}$. Esta joya, fue adquirida por 40 escudos, según factura del siete de octubre de 1562, por Eleonora de Toledo, esposa de Cosme I de Médicis a Gasparo Miseroni, aunque posiblemente este lapidario milanés, discípulo de Trezzo, no sea más que el intermediario de la compra. No la data, pero para los estudiosos italianos habría sido hecha entre 1550 y 1557 , más cerca de la última fecha, si observamos el rostro del Príncipe, que parece tener alrededor 12-14 años.

No es esta la única joya con los retratos de Felipe y Carlos, la Bibliothèque Impériale de París, actual Gabinete de Medallas,conservaba un zafiro blanco octogonal prolongado, con un intaglio, (huecograbado ), de sus perfiles enfentados y separados por una Cruz, alzada sobre lo que parecen los pétalos de una flor. En el bisel, y también grabada, hay la siguiente inscripción: «PHI. REX. HISP. CARO. PHIL. FILI. 1566» (Felipe Rey de España. Carlos hijo de Felipe. 1566). Para Ernest Babelon ${ }^{39}$, Mariette ${ }^{40}$ y Chabouillet es obra de Trezzo, señalando el último, que tenía una montura de oro esmaltado con granates ${ }^{41}$. También Dalton le dedica unas líneas en las que no aporta nada nuevo a lo ya expuesto ${ }^{42}$. ¿Es de la mano de Trezzo? La falta de argumentación de los estudiosos citados y la no localización de ningún documento al respecto, hacen muy difícil la adjudicación, mas aún cuando el autor podía haber añadido sus iniciales a la inscripción.

Hay por último y para finalizar, un camafeo que tiene a Felipe II como protagonista de una escena triunfal, en la que de cuerpo entero y de perfil a la derecha, se nos muestra sentado en un carro tirado por caballos, coronado por la Victoria y acompañado de soldados romanos, dirigiendose hacia un Arco de Triunfo. Se trata de una calcedonia oval, guardada con el n. 106 en el Museo Degli Argenti, que también vino a la exposición del Prado, su catálogo y Massinelli y Tuena, proporcionan bastantes datos sobre él, cuya montura es un simple cerco de oro con una anilla en la base, de la que sin lugar a dudas, colgaría una perla hoy perdida. Lleva la firma «DNICVS ROMANVS F.» (Hecho por Doménico Romano) y pertenecía a la colección del Obispo Viterbo, a quien se le habría regalado, por su labor diplomática entre España y Fran-

\footnotetext{
${ }^{31}$ Ibidem, p. 251 y Angulo, Diego: Catálogo de las alhajas del Delfín. Madrid, Museo del Prado, 1989, p. 23.

${ }^{32}$ Babelon, Ernest: La gravure en pierres fines, camées et intailles. París, Ancienne Maison Quantin, Librairies- Imprimeries Réunis, s/a, p. 258.

${ }^{33}$ Somers Coks y otros : Op. cit., p. 55, n. $^{\circ} 25$.

${ }^{34}$ Rossi, Filippo: Op. cit., tav. 64 b.

${ }^{35}$ Hackenbroch, Yvonne: Renaissance..., p. 317.

${ }^{36}$ Babelon, Jean: Op. cit., p. 242 , nota 3 y Aschengreen Piacenti, Cristina: Op. cit., p. 182, n. $^{\circ} 984$.

${ }^{37}$ VVAA.: Felipe II..., pp. 548- 548, n. ${ }^{\circ} 1191$.

${ }^{38}$ Massinelli, Anna María y Tuena, Filippo: El Tesoro de los Medici. Madrid, Editorial Anaya S.A. 1992, p. 74 y Tuena, Filippo: «Il tesoro dei Medici. Collezionismo a Firenze dal Quattrocento al Seicento». Art e Dossier.n. ${ }^{\circ} 18$ ( 1987), pp. 46- 47.

${ }^{39}$ Babelon, Ernest: Op. cit., p. 258, pl. IX, n. ${ }^{\circ} 10$.

${ }^{40}$ Mariette, Pierre Jean: Traité des pierres gravées. París, L'Imprimerie de l'auteur, MDCCL, Vol II, lám. 119.

${ }^{41}$ Chabouillet, M.: Op. cit., p. 341 , n. ${ }^{\circ} 2488$.

${ }^{42}$ Dalton, O.M.: Op. cit., p. 51, n 381.

AEA, LXXV, 2002, 297, pp. 23 a 38
} 
cia, en 1556 y quien propuso su venta a Francisco I de Médicis en 1565, hecho que no se realizó hasta $1575^{43}$. En cuanto al año de ejecución y al acontecimiento que narra, ninguno se pronuncia, pero se comprende que, si la joya se regaló en 1556, tuvo que ser hecha o en ese mismo año o antes, posiblemente en 1551, cuando por el Acuerdo de Augsburgo, Fernando se comprometía a que Felipe fuese elegido Rey de Romanos, suceso al que posiblemente haga alusión el camafeo ${ }^{44}$.

Las piezas analizadas son sin lugar a dudas muchas, sobre todo si tenemos en cuenta que las joyas del siglo XVI fueron destruidas en numerosas ocasiones, bien para hacer con sus materiales piezas más «modernas» o bien para, en el caso del oro, acuñar monedas con las que poder comprar armas o cubrir cualquier necesidad. Pero en los inicios de este trabajo se ha comentado que hay también otras «joyas-retratos» a tener en cuenta, son las descritas por los documentos de la época y las que aparecen en pinturas, sobre todo y valga la redundancia, de retratos.

De los documentos consultados, se ha creído interesante citar sólo algún ejemplo puntual, que, por la descripciones, permita relacionarlo con las joyas expuestas.

$\mathrm{Y}$ así dice el primero: «Un retrato de oro de medio relieve en redondo, del emperador Carlos Quinto sobre una piedra de jaspe, metido en una caxuela con tapador; que pessa dicho retrato de piedra, como está, cinco castellanos y un tomín y seys granos. Tasado en ocho ducados» ${ }^{45}$.

¿Se trata del medallón del Metropolitan? Pues es posible, ya que el heliotropo no es sino jaspe sanguíneo, una calcedonia verde obscura con manchas rojas de cornalina. Sin embargo, se puede argumentar que aquel era ligeramente oval y este redondo, y que no hay alusiones al lapislázuli ni a la inscripción ¿añadidos posteriores?, y lo que parece desvanecerse es la atribución a Leoni, porque un dato tan relevante seguro que iría acompañando a la descripción.

Otro documento interesante es el siguiente: «Un retrato de camafeo del rostro del rey $\mathrm{Fe}$ lipe segundo guarnescido de oro esmaltado de colores con quatro esmeraldas en punta, en una bolsilla de ambar guarnescida de plata y seda amarilla». A la izquierda: «retrato de camafeo cargado a $f 66$ en partida 11390» ${ }^{46}$.

No se conserva, pero debía de ser un ejemplar en la línea de algunos de los que hemos comentado, cercano al camafeo de Carlos en una montura de rubíes.

Merece igualmente destacarse la siguiente joya por su atribución a Trezzo:

«Un retrato de medio reliebe del Rey don Phellype nuestro señor, de camapheo, del pecho arriba, el rostro de camapheo blanco y lo demás pardo, en forma aobada, con un letrero esculpido a la redonda que dize: "Philippus segundo Dey gracia, hispaniarum rex. catho". con cerco de oro esmaltado de blanco negro y azul y otros colores, lisso, con assa y reassa de oro; que pessa como está dicho, veynte y dos castellanos, tres tomines y seys granos, metido en cajuela cubierta de cuero negro, forrada en terciopelo negro; hízole Jacobo de Trezo. Tasada en quarenta ducados» ${ }^{47}$.

Lástima que ninguno de los camafeos estudiados se ajuste a esta descripción, porque en ese caso sí podríamos afirmar que era un trabajo de Trezzo, y en relación con el magnífico

\footnotetext{
${ }^{43}$ Massinelli, Anna María y Tuena, Filippo: Op. cit., p. 120 y VVAA.: Felipe II..., p. 369, n 70.

${ }^{44}$ Fernández Álvarez, Manuel: Op. cit., p. 292.

${ }^{45}$ Sánchez Cantón, Francisco Javier: Archivo Documental Español. Inventarios Reales: Bienes Muebles que pertenecieron a Felipe II. Madrid, Real Academia de la Historia, 1956- 1959, Vol. II, p. 175, n. 352 (502).

${ }^{46}$ «Archivo General de Simancas» (AGS). Patronato Real, caja 31, n. ${ }^{\circ} 28$, folios 214 r y 266 r. 1581. «Testamento de la Emperatriz de Hungría y relación de bienes y su distribución».

${ }^{47}$ Sánchez Cantón, Francisco Javier: Op. cit., Vol. II, p. 174, n. ${ }^{\circ} 3546$ (496), Müller, Priscilla E.: Op. cit., p. 50; VV AA.: Felipe II..., p. 549, n. ${ }^{\circ}$ 191; Babelon, Jean: Op. cit., p. 241.
} 


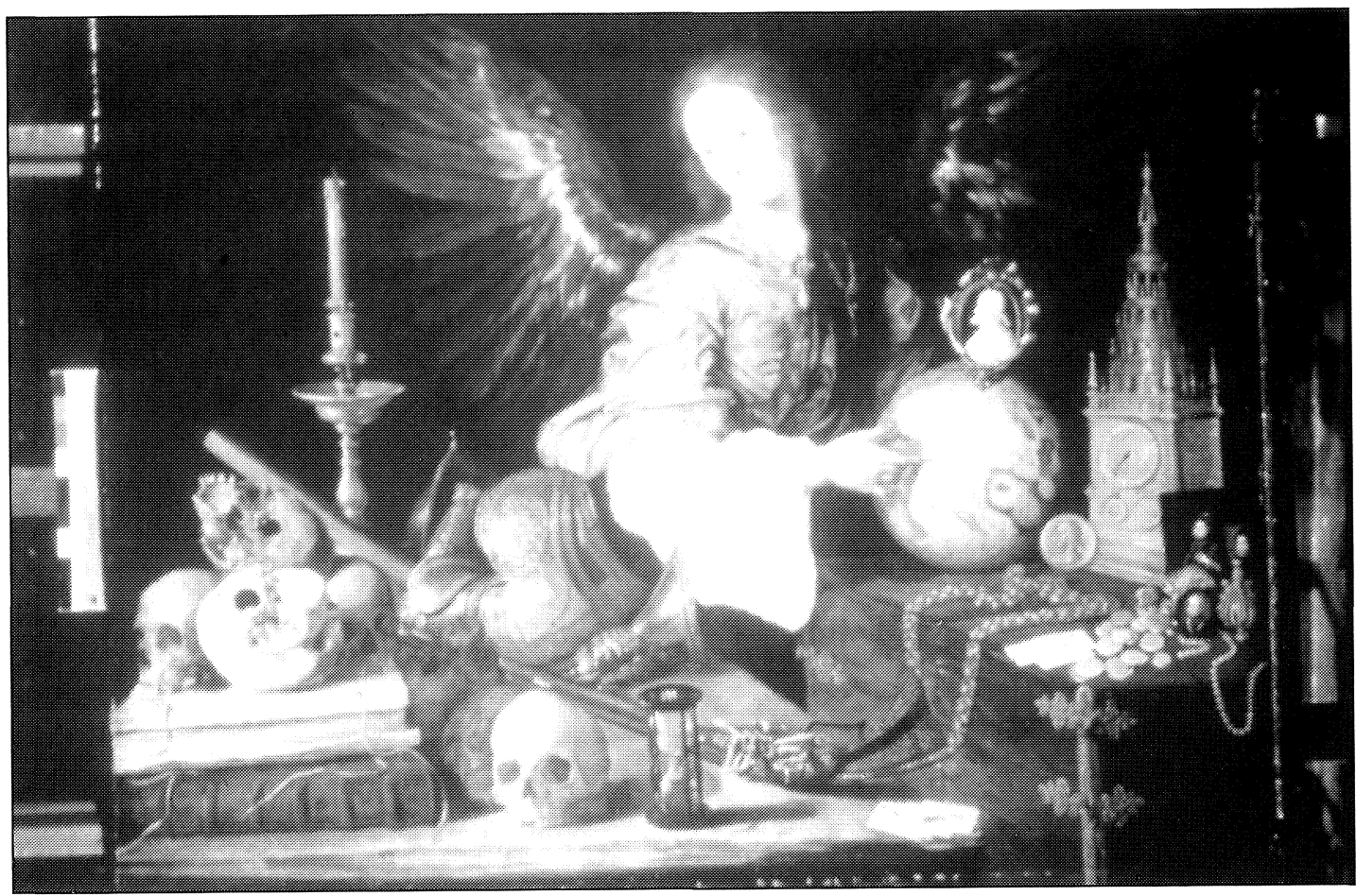

Fig. 11. «Vanitas», Antonio de Pereda, 1635- 1637. Kunsthistorisches Museum, Viena.

tallador al servicio del Rey, es interesante citar el siguiente documento que nos le presenta no sólo como tal, sino también como comprador y tal vez coleccionista:

«Dattas de lo vendido en Madrid. Reçibesele en quenta una medalla de camafeo de dos fazes contenida en la partida del cargo de esta quenta en xxiij dias del dicho mes de septiembre del dicho año de 1568 (?) se bendio a mizer Jacome entallador de camafeos y cristales de su mag.(estad) la qual medalla estaba guarnecida de oro y estaba tasada en treinta ducados y se le bendio por treinta ducados como fijo por fee Juan Rodríguez escribano que asistio ala almoneda q(ue) se hizo de sus bienes y por el libro della de los quales ducados mi an de dar quenta los dichos Antonio Gonzalez y Fernando Delgadillo a cuyo cargo estuvo la dicha almoneda venta y buen recaudo(?) della por comision de los dichos testamentarios» ${ }^{48}$.

Para finalizar, se ha elegido un documento realmente importante, en él se describe una joya sobre la que hay numerosas referencias y dice así:

«Un retrato del Rey, nuestro señor, de camafeo, de pecho, arriba, de medio reliebe, armado, con una guirnalda de flores en la cabeza, puesto sobre una piedra negra, grande, aobada, guarnecida de una chapa de oro en redondo, esmaltada de negro y sobre ella otra guarnición esmaltada de blanco y negro, con unas florescillas a los lados, labrados de frutas, y unos cartoncitos por toda guarnición; esmaltados de dibersos colores y en lo alto, de remate una bola y sobre ella un águila de oro esmaltado de pardo, con un assa en la dicha guarnición para colgarse y en lo baxo un maxcarón metido en una caxa cubierta de terciopelo morado. Tasado en ciento y veynte ducados» ${ }^{49}$.

Para Muller, este camafeo es similar al que aparece en la pintura de Antonio de Pereda, «Vanitas» $\mathrm{o}$ «Alegoria del paso del tiempo», en el Kunsthistorisches (Fig. 11), aunque advierte

\footnotetext{
${ }^{48}$ AGS. Contaduría Mayor de Cuentas, $1^{a}$ Época, Legajo 1145, Folio 18 v y Cargo en 18 r. 1568. «Inventario de los bienes que quedaron de su Magestad en Yuste al tiempo de su fallecimiento».

${ }^{49}$ Sánchez Cantón, Francisco José: Op. cit.,Vol II, p. 174, n. ${ }^{\circ} 3545$ ( 495)
}

AEA, LXXV, 2002, 297, pp. 23 a 38 
que el retrato es de Carlos $\mathrm{V}^{50}$. Y ciertamente la descripción que el documento hace de la joya se identifica plenamente con la del cuadro, en la que no sólo Muller ve a Carlos V, sino también otros estudiosos como Pérez Sánchez, quien fecha la pintura entre 1635- 1637 y señala que: «...encierra seguramente sutiles alusiones a la Casa de Austria y al César Carlos, no solo por su inmediata y tan evidente presencia en el rico camafeo que sostiene el Ángel-Genio, mostrándolo precisamente sobre el universo que dominó, sino por el paralelo surgido con la medalla de Augusto... ${ }^{51}$. Lo curioso es que Ponz en su Viaje de España a finales del siglo XvIII, pudo contemplar el camafeo del documento en el Guardajoyas del Palacio Real y escribe sobre él: «... un gran camafeo con el retrato relevado de Felipe II en marco de oro, en la parte superior adornado de un águila y en la inferior de un mascaroncillo» ${ }^{52}$. ¿Había dos camafeos con la misma montura? No es probable, además, una observación detallada del camafeo pintado, permite llegar a la conclusión de que el retratado no es Carlos, sino Felipe II, por lo tanto, Pereda pintaría en su «Vanitas» el camafeo documentado, que Ponz vería en el Palacio Real de Madrid, y del que, por desgracia, no hay ninguna referencia a su actual paradero. No parece ser Carlos, porque el retrato, de perfil a la izquierda, es de un hombre mayor de cincuenta y ocho años, que fueron los que tenía el Emperador cuando murió, es un rostro cercano a los setenta, y además, comparando la forma de las cabezas ya vistas en los anteriores camafeos, la de Carlos era más redondeada, mientras la de Felipe es algo más alargada, como la que se ve aquí, incluso se le aprecia ese gesto característico de arquear las cejas. ¿Pierde el cuadro con Felipe? No, además otros detalles pueden hacer referencia a su persona, así, los pequeños retratos femeninos que descansan sobre la mesa a la derecha, por el peinado y los ropajes, recuerdan a tres mujeres claves en la vida del Rey, sus hijas Isabel Clara Eugenia y Catalina Micaela, y su hermana Juana de Portugal, y la bola del mundo, sobre la que reposa el camafeo, es similar a la reproducida en los trabajos del cartógrafo Christian Sgrooten, quien estuvo varios años al servicio del Rey ${ }^{53}$, pudiendo aludir a esos «dominios sobre los que nunca se ponía el sol», finalmente, la moneda de Augusto, puede ser una referencia a Carlos o al propio Felipe, quien en su lecho de muerte pronunció ante su hijo, el futuro Felipe III, unas palabras invitándole a meditar sobre dónde paraban en última instancia el poder y la gloria de los reyes.

Y fueron, precisamente, los seres queridos de Carlos y Felipe los que se hicieron retratar con su imágenes. Doña Juana aparece en varios retratos, con joyas de este tipo colgadas de las puntas de su toca de viuda, el primero, en el Isabelle Stewart Gadner Museum de Boston, de mano de Sofonisba Anguisola, de hacia 1561, muestra un camafeo oval con la imagen de su padre Carlos, ya mayor, coronado de laurel, de perfil a la derecha, trabajado en blanco sobre fondo obscuro, en una montura de oro con roleos y cartelas recortadas. En el segundo, obra de Sánchez Coello, en el museo de Bellas Artes de Bilbao, aparece una miniatura oval, de su hermano Felipe II, en una montura de oro decorada con flores de lis en los ejes; el Rey aparece de perfil a la derecha, aunque ligeramente girado hacia el centro, con gorra y traje negro, con una edad aproximada a la que tendría en la fecha en que se pintó el cuadro, hacia 1557: Treinta años. El tercer retrato de Juana, en las Descalzas Reales, es su imagen mortuoria esculpida por Pompeo Leoni, en 1574 (Fig. 12). Aquí la Reina de Portugal lleva un camafeo con la imagen de perfil a la derecha de su hermano Felipe, que para Jean Babelon, habría sido trabajo de Trezzo ${ }^{54}$.

\footnotetext{
${ }^{50}$ Müller, Priscilla E.: Op. cit., p. 50.

${ }^{51}$ Pérez Sánchez, Alfonso E.: D. Antonio de Pereda (1611-1678) y la Pintura Madrileña de su tiempo", Madrid, Salas de Exposiciones del Palacio de Bibliotecas y Museos, Diciembre 1978- Enero, 1979, catálogo, n. ${ }^{\circ} 7$.

${ }^{52}$ Ponz, Antonio, Viaje de España. Madrid, Aguilar, 1947, Libro VI, p. 537, n. ${ }^{\circ} 83$.

${ }^{53}$ VV.AA.: Felipe II..., pp. $641-645$, n. ${ }^{\circ} 260.1$ y 260.2

${ }^{54}$ Babelon, Jean: Op. cit., p. 203.
} 
Conserva también las Descalzas, dos retratos de la que fuese Regente de España, son dos pinturas, al parecer sin atribución, en las que la hija y hermana de los Monarcas lleva joyas similares pinjando de las puntas de su toca de viuda.

Isabel de Valois, la tercera esposa del Rey, también aparece en un retrato con una de estas joyas. La pintura, fechada hacia 1561, obra de Sofonisba Anguissola, en el Museo del Prado, muestra a la Reina sujetando con su mano derecha una miniatura oval del Rey, de perfil a la derecha, en una montura con roleos de oro esmaltados de rojo y que tal vez pueda ser «el medallón con el retrato del novio» que el Duque de Alba le llevó, de parte de Felipe, junto con otras joyas, en un cofrecillo a París antes de las bodas ${ }^{55}$.

Los dos ultimos retratos son de las hija favorita del Rey, Isabel Clara Eugenia: En el primero de ellos, en el Museo del Prado (Fig. 13), de Sánchez Coello, pintado alrededor de 15851588, la Infanta, que aparece junto a Magdalena Ruiz, sujeta con su mano derecha un camafeo oval, de su padre, de perfil a la derecha, en blanco sobre fondo obscuro, con una montura en forma de doble cerco de oro, esmaltado de blanco el más exterior. La imagen que aquí se nos ofrece del Monarca, recuerda mucho la ya estudiada en el camafeo que tiene en la otra cara el retrato del Príncipe Carlos, aunque aquí se le ve más mayor y no coinciden por completo los detalles de la armadura. En el segundo retrato de la Infanta, pintado por Bartolomé González a comienzos del siglo xvir, en el Monasterio de El Escorial, vemos a una mujer madura que sujeta entre sus manos un medallón oval, colgado de su cuello por una cadena de oro, con la miniatura de su padre montada en un cerco igualmente de oro. El Rey, de perfil a la derecha, tocado por un sombrero alto, es un anciano, y recuerda extraordinariamente al retrato que le hizo Pantoja de la Cruz en 1593-1594, también en el Monasterio de El Escorial y por lo tanto, aunque con variantes en cuanto a la dirección de su rostro, al camafeo citado por Jean Babelon.

Y de esta manera es cómo han pasado a la Joyería del Renacimiento las imágenes de Carlos V y Felipe II, cuyos reinados hemos recordado a finales del siglo xx y comienzos del XXI, como grandes acontecimientos de nuestra Historia.

\footnotetext{
${ }^{55}$ Horcajo Palomero, Natalia: «Reinas y joyas en la españa del siglo XVI» en IX Jornadas de Arte: El Arte en las Cortes de Carlos V y Felipe II, (Madrid, 1998 ), Madrid, C.S.I.C. , 1999, p. 146.
}

AEA, LXXV, 2002, 297, pp. 23 a 38 